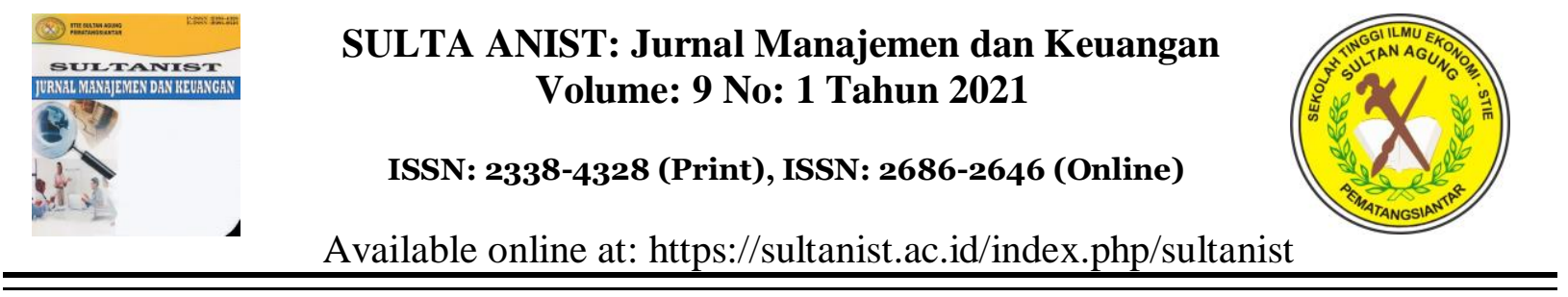

\title{
DAMPAK KARAKTERISTIK INDIVIDU TERHADAP KINERJA PEGAWAI PADA DINAS KEPENDUDUKAN DAN PENCATATAN SIPIL KOTA PEMATANGSIANTAR
}

\author{
Darwin Lie $^{1)^{*}}$, Efendi ${ }^{2)}$, Sudung Simatupang ${ }^{3)}$, Syafira Zulkarnaen ${ }^{4)}$, Sofiyan ${ }^{5)}$ \\ ${ }^{1234}$ Program Studi Manajemen, STIE Sultan Agung. Jalan Surabaya No. 19, Kota Pematangsiantar, \\ Sumatera Utara, 21118, Indonesia. \\ *E-mail: syafirazulkarnaen@gmail.com, darwin@stiesultanagung.ac.id, efendi@stiesultanagung.ac.id, \\ sudungsimatupang@stiesultanagung.ac.id, sofiyan@stiesultanagung.ac.id
}

\begin{abstract}
Abstrak
Tujuan dari penelitian ini adalah untuk mengetahui pengaruh karakteristik individu terhadap kinerja pegawai pada Dinas Kependudukan dan Pencatatan Sipil Pematangsiantar yang dilakukan dengan pendekatan parsial. Pengumpulan data dilakukan dengan kuesioner, wawancara dan dokumentasi. Uji instrumen penelitian yang digunakan adalah uji validitas dan reliabilitas. Teknik analisis data terdiri dari uji normalitas, analisis deskriptif kualitatif dan deskriptif kuantitatif. Hasil dari penelitian dapat dijabarkan sebagai berikut: Disiplin kerja, karakteristik individu dan kinerja pegawai sudah baik. Terdapat pengaruh positif dan signifikan antara dari karakteristik individu terhadap kinerja pegawai pada Kantor Dinas Kependudukan dan Pencatatan Sipil Pematangsiantar. Terdapat hubungan yang kuat dan positif antara karakteristik individu terhadap kinerja pegawai.
\end{abstract}

Kata kunci: karakteristik individu, kinerja pegawai, pendekatan parsial

\begin{abstract}
The purpose of this study was to determine the effect of individual characteristics on employee performance at the Pematangsiantar Department of Population and Civil Registration both simultaneously and partially. Data collection was carried out by means of questionnaires, interviews and documentation. The research instrument test used was the validity and reliability test. The data analysis technique consisted of normality test, qualitative descriptive analysis and quantitative descriptive analysis. The results of the research can be described as follows: Work discipline, individual characteristics and employee performance are good. There is a positive and significant influence between individual characteristics on employee performance at the Pematangsiantar Office of Population and Civil Registration. There is a strong and positive relationship between individual characteristics and employee performance.
\end{abstract}

Keywords: individual characteristics, employee performance, partial approach

Article History: Received: 21 Mei 2021 Revised: 22 Mei $2021 \quad$ Accepted: 23 Mei 2021 


\section{PENDAHULUAN}

Kinerja pegawai menjadi perihal utama yang perlu diperhatikan oleh setiap instansi, Berdasarkan Peraturan Pemerintahan Nomor 30 Tahun 2019 yang dinilai berdasarkan dimensi sasaran kinerja pegawai (SKP) terdiri dari kuantitas, kualitas, waktu, dan biaya. Sedangkan Perilaku Kerja (PK) yang terdiri dari orientasi pelayanan, komitmen, inisiatif kerja, kerjasama dan kepemimpinan. Kinerja pegawai pada Dinas Kependudukan dan Pencatatan Sipil Pematangsiantar belum optimal, berdasarkan hasil wawancara dengan Kabid Pengelolaan Informasi Administrasi Kependudukan Dinas Kependudukan dan Pencatatan Sipil Pematangsiantar pada dimensi SKP (Sasaran Kinerja Pegawai) dimana masih terdapat pegawai yang tidak tepat waktu saat melaksanakan tugas dan pekerjaannya. Selain itu, dari dimensi PK (Perilaku Kerja) dimana orientasi pelayanan belum optimal sehingga menyebabkan konflik antara masyarakat dengan pegawai akibat tingginya tingkat emosi antar kedua belah pihak.

Salah satu faktor yang diduga mempengaruhi kinerja adalah karakteristik individu. Sesuai pendapat dari penelitian Desyinta, dkk (2019) yang memaparkan bahwa terdapat pengaruh positif antara karakteristik individu terhadap kinerja pegawai, semakin baiknya karakteristik individu seorang pegawai, semakin tinggi pula kinerja yang dapat dicapai. Adapun dimensi karakteristik individu yaitu tingkat persetujuan (agreeableness), tingkat keseriusan dan kesadaran (conscienctiousness), tingkat emosi yang negatif (negative emosional), tingkat keleluasan dan kenyamanan (extraversion), tingkat keterbukaan (openness).

Fenomena pada karakteristik individu pada Dinas Kependudukan dan Pencatatan Sipil Pematangsiantar belum optimal. Hal ini terjadi pada dimensi tingkat emosi yang negatif dimana terdapat pegawai yang kurang mampu mengendalikan emosi saat berhadapan dengan masyarakat yang menyampaikan keluhannya, masyarakat yang menyampaikan keluhan dengan suara membentak menyebabkan pegawai tersinggung dan mengeluarkan suara yang lantang sehingga mengganggu konsentrasi pegawai lainnya. Pada dimensi tingkat keseriusan dan kesadaran, dimana masih terdapat pegawai yang bersendagurau saat bekerja atau kurang fokus saat melakukan pekerjaan sehingga menghasilkan pekerjaan yang kurang maksimal. Sesuai latar belakanng diatas, dapatdinyatakan adanya perbedaan harapan dengan kenyataan, sehingga memotivasi penulis untuk melakukan penelitian ini.

\section{LANDASAN TEORI}

\section{Karakteristik Individu}

Sumber daya manusia adalah aset suatu organisasi, sumber daya manusia yaitu orang-orang yang memberikan waktu, tenaga, bakat, kreativitas, dan usaha mereka kepada organisasi agarorganisasi dapat tetap mempertahankan eksistensinya (Sahir et al., 2020). Setiap manusia manusia mempunyai karakteristik individu yang berbeda-beda antara satu dengan yang lainnya. Rahman (2013), menyatakan bahwa karakteristik individu merupakan ciri khas yang ditunjukkan perbedaan seseorang tentang motivasi, inisiatif,kemampuanuntuk tetaptegar menghadapi tugas atau memecahkan masalah atau bagaimana menyesuaikan perubahan yang baik dengan lingkungan yang mempengaruhi kinerja individu. Sedangkan Robbins dan Timothy (2017), berpendapat bahwa karakteristik individu merupakan kepribadian yang membentuk preferensi atau imbalan, gaya komunikasi, reaksi kepada pemimpin, gaya negosiasi yang mempengaruhi organisasi.

Selain itu, Sule dan Kurniawan (2010), menyatakan karakteristik individu merupakan sikap dan perilaku individu didalam perusahaan untuk mengimplementasikan rencana organisasi. Karakteristik individu direpresentatifkan sebagai ciri khas setiap individu yang disebabkan oleh latar belakang yang 


\section{SULTANIST: Jurnal Manajemen dan Keuangan, Vol 9 (1), Juni 2021}

berbeda-beda. Hasil pandangan ahli tersebut maka penulis menarik kesimpulan bahwasanya karakteristik individu bagian dari karakter setiap orang yang memiliki sifat dan ciri khas yang memberikan perbedaan antara satu dengan yang lain tentang motivasi serta kemampuan untuk tetap kuat dalam mengahadapi tantangan dan masalah yang berbeda dalam kehidupan.

\section{Kinerja Pegawai}

Kinerja merupakan hasil kerja yang telah dilaksanakan oleh pegawai untuk mencapai tujuan organisasi, jika kinerja pegawai tidak optimal maka tujuan suatu organisasi tidak tercapai secara sempurna. Kinerja mempengaruhi seberapa baiknya pegawai memberikan kontribusi kepada organisasi. Bangun (2012), mengemukakan kinerja (performance) merupakan hasil pekerjaan yang dicapai seseorang berdasarkan persyaratan-persyaratan pekerjaan (job requirement). Sedangkan Zainal,dkk (2015), mengemukakan bahwa kinerja merupakan suatu istilah secara umum yang digunakan untuk sebagian atau seluruh tindakan atau sejumlah standar seperti biaya-biaya masalalu atau yang diproyekskan, dengan dasar efisiensi, pertanggungjawaban atau akuntabilitas manajemen dan semacamnya.

Selain itu, Kasmir (2016), menyatakan kinerja merupakan hasil kerja dan perilaku kerja yang telah dicapai dalam menyelesaikan tugas-tugas dan tanggung jawab yang diberikan dalam suatu periode terakhir". Hasil kesimpulan dari pandangan ahli diuraikan bahwa kinerja merupakan suatu keahlian yang dimiliki individu kerja, cara individu dalam mengeksplorasi pekerjaan dan bagaimana individu melakukan tugas serta bagaimana wewenang dilaksanakan dengan baik dan benar (Lie et al., 2019).

Penilaian kinerja dilakukan oleh setiap organisasi kepada seluruh pegawai untuk dijadikan bahan evaluasi atau menilai pegawai dalam melaksanakan tugasnya. Berdasarkan Peraturan Pemerintah (PP) Nomor 30 Tahun 2019 tentang penilaian kinerja yaitu "suatu proses sistematis yang terdiri dari perencanaan kinerja, pelaksanaan, pemantauan, dan pembinaan kinerja, penilaian kinerjatindak lanjut, dan sistem informasi kinerja" Menurut Kasmir (2016), mengemukakan penilaian kinerja merupakan suatu sistem yang dilakukan secara periodik untuk meninjau dan mengevaluasi kinerja individu. Sedangkan Zainal, dkk (2015), menyatakan bahwa penilaian kinerja mengacu pada suatu sistem formal dan terstruktur yang digunakan untuk mengukur, menilai dan mempengaruhi sifatsifat yang berkaitan dengan pekerjaan, perilaku dan hasil, termasuk tingkat kehadiran.

\section{METODE}

Penelitian ini menggunakan desain penelitian kepustakaan dan penelitian lapangan. Populasi pada penelitian ini adalah seluruh pegawai Dinas Kependudukan dan Pencatatan Sipil Pematangsiantar yang berjumlah 35 pegawai dan seluruhnya dijadikan sampel. Jenis data yang digunakan adalah data kualitatif dan data kuantitatif. Sumber data di pakai adalah data primer dan data sekunder. Pengumpulan data dilakukan dengan kuesioner, wawancara dan dokumentasi. Uji instrumen penelitian yang digunakan adalah uji validitas dan reliabilitas. Teknik analisis data terdiri dari uji normalitas, analisis deskriptif kualitatif dan deskriptif kuantitatif.

\section{HASIL DAN PEMBAHASAN}

\section{Hasil Analisis Kualitatif}

\section{Karakteristik Individu}

Berdasarkan hasil kuesioner dan penelitian dapat disimpulkan bahwa karakteristik individu pada Disdukcapil Pematangsiantar berada ditaraf rataan 3,54 dengan parameter jawaban baik. Dalam perhal ini karakteristik individu pada Kantor Dinas Kependudukan dan Pencatatan Sipil Pematangsiantar harus lebih ditingkatkan lagi. Pada indikator keseriusan dalam bekerja dengan taraf rataan 3,03 dengan parameter jawaban cukup baik. Sebaiknya 


\section{SULTANIST: Jurnal Manajemen dan Keuangan, Vol 9 (1), Juni 2021}

pegawai lebih meningkatkan keseriusannya dan tingkat fokusnya saat menyelesaikan pekerjaan yang diberikan. Pada dimensi tingkat emosi yang negatif dengan indikator tingkat ketenangan dalam bekerja dengan taraf rataan 3,23 dengan parameter jawabancukup baik. Dianjurkan pimpinan membuat alat peredam suara diruang bekerja agar pegawai lebih nyaman dan tenang dalam menyelesaikan pekerjaannya. Pada indikator pengendalian emosi dengan taraf rataan 3,17 dengan parameter jawaban cukup baik. Sebaiknya pegawai lebih bersikap tenang dalam situasi apapun, baik dalam menerima beban kerja maupun keluhan dari masyarakat. Pada dimensi tingkat keterbukaan dengan indikator menerima ide ide baru dari rekan kerja dikantor dengan taraf rataan 3,37 dengan hasil jawaban cukup baik. Sebaiknya pimpinan membuat grup diskusi untuk melatih bawahan dalam menuangkan ideidenya sehingga pegawai lebih kreatif lagi dalam bekerja

Dari uraian diatas bisa dinyatakan tentang karakteristik individu Dinas Kependudukan dan Pencatatan Sipil Pematangsiantar sudah baik. Namun apabila hal diatas lebih diperhatikan maka, akan mengalami peningkatan dalam memberikan pelayanan pada masyarakat. Hal tersebut akan memberikan rasa puas kepada masyarakat.Perihal ini didukung oleh dimensi karakteristik individu menurut Sule dan Kurniawan (2010).

\section{Kinerja Pegawai}

Berdasarkan hasil kuesioner dan penelitian makadisimpulkan bahwaKinerja Pegawaipada Kantor Dinas Kependudukan dan Pencatatan Sipil Pematangsiantar dengan taraf rataan 3,67 dengan parameter jawaban baik. Dalam perihal ini Kinerja Pegawai pada Kantor Dinas Kependudukan dan Pencatatan Sipil Pematangsiantar harus lebih ditingkatkan lagi. Pada tingkat pencapaian kerja dengan taraf rataan 3,46 pada parameter jawaban baik. Sebaiknya pegawai lebih meningkatkan lagi kemampuan dalam membagi waktunya terhadap pekerjaan dan menyelesaikan pekerjaan sesuai dengan waktu yang telah ditentukan.

Pada ketepatan penyelesaian pekerjaan pada taraf rataan 3,31 dengan parameter jawaban cukup baik. Sebaiknya pimpinan dan pegawai lebih memerhatikan ketersediaan blanko yang diperlukan agar pekerjaan tidak terbengkalai. Selanjutnya efisiensi waktu dalam menyelesaikan pekerjaan berada pada taraf rataan 3,37 dengan parameter jawaban cukup baik. Sebaiknya pegawai dinas lebih memperhatikan kelengkapan perlengkapan operasional dan pegawai harus mampu memanajemen waktu terhadap pekerjaannya. Pada indikator kemampuan dalam mengalokasikan biaya berada pada taraf rataan 3,46 parameter jawaban baik. sebaiknya pegawai lebih mengoptimalkan dana yang diberikan untuk menyelesaikan pekerjaan mereka. Kemudian dimensi perilaku kerja dengan indikator sikap dalam pelayanan berada pada taraf rataan 3,34 dengan parameter jawaban cukup baik. sebaiknya pegawai lebih bersabar dalam melayani keluhan masyarakat. Pada indikator kualitas pelayanan berada pada taraf rataan 3,40 dengan parameter jawaban cukup baik, disebabkan adanya beberapa pegawai yang marah marah saat melayani masyarakat akibat kurang pahamnya dalam pengurusan berkas.

Kemudian pada inisiatif dalam menyelesaikan pekerjaan berada pada taraf rataan 3,66 pada parameter jawaban baik,Sebaiknya pegawai lebih meningkatkan inisiatifnya dalam bekerja tanpa harus adanya perintah dari pimpinan. Dari uraian tersebut bisa dinyatakan tentang kinerja pegawai Dinas Kependudukan dan Pencatatan Sipil Pematangsiantar sudah baik. Namun apabila hal diatas lebih diperhatikan maka, akan mengalami peningkatan dalam memberikan pelayanan pada masyarakat. Hal tersebut akan memberikan rasa puas kepada masyarakat.Perihal ini sesuai dengan dimensi kinerja pegawai menurut Wirawan (2014). 


\section{Hasil Analisis Kuantitatif}

\section{Regresi Linier Sederhana}

Untuk menganalisis pengaruh antar variabel digunakan analisis regresi linier berganda dengan bantuan SPSS berikut ini: dijelaskandan karakteristik individu sedangkan sisanya $36,5 \%$ disebabkan faktor luar seperti variabel kepuasan kerja, loyalitas pegawai dan proses yang tidak dibahas pada variabel ini.

\section{Pengujian Hipotesis}

Uji hipotesis yang digunakan dengan Tabel 1. Hasil Regresi Linier berganda

\begin{tabular}{|c|c|c|c|c|c|}
\hline & \multirow{2}{*}{ Model } & \multicolumn{2}{|c|}{$\begin{array}{c}\text { Unstandardized } \\
\text { Coefficients }\end{array}$} & \multicolumn{2}{|c|}{$\begin{array}{l}\text { Standardizedj t dilakukan untuk membuktikan hipotesis } \\
\text { Coefficienty } \mathrm{ng} \text { ngajukan sebelumnya. Adapun syarat } \\
\text { p\&ngujian dengan melihat nilai signifikansi }\end{array}$} \\
\hline & & $B$ & $\begin{array}{c}\text { Std. } \\
\text { Error }\end{array}$ & Beta $\quad \begin{array}{c}\mathrm{pe} \\
\leq\end{array}$ & $\begin{array}{l}\text { ngujian dengan melihat nilai signifikansi } \\
\text { (lebih kecil atau sama dengan) } 0,05 \text {, maka }\end{array}$ \\
\hline 1 & $($ Constant $)$ & 32.964 & 4.546 & & potesis diterima. Hasil pengujian hipotesi \\
\hline & $\begin{array}{l}\text { Karakteristik } \\
\text { Individu }\end{array}$ & .485 & .084 & .708 & $\begin{array}{l}\text { Tunjkkan tabel di bawah: } \\
\text { Tabel 3. Hasil Pengujian Hipotesis }\end{array}$ \\
\hline
\end{tabular}

a. Dependent Variable: Kinerja_Pegawai

Sumber: pengolahan data

Perolehan pengelolaan data kuesioner sesuai tabel 1 didapatkan persamaan regresi sebagai berikut: $\hat{\mathrm{Y}}=32,964+0,485 \mathrm{X} 1$, maknanya terdapat pengaruh positif antara karakteristik individu terhadap kinerja pegawai pada Kantor Dinas Kependudukan dan Pencatatan Sipil Pematangsiantar.

\section{Korelasi dan Koefisien Determinasi}

Untuk melihat keeratan hubungan antar variabel dan kontribusi variabel bebas terhadap naik turunnya variabel terikat dapat dilihat dari hasil analisis korelasi dan koefisien determinasi melalui program SPSS berikut:

Tabel 2. Hasil Korelasi dan Determinasi

\begin{tabular}{|c|c|c|c|c|c|}
\begin{tabular}{rl|l} 
Mo \\
del
\end{tabular} & $\mathrm{R}$ & $\begin{array}{c}R \\
\text { Square }\end{array}$ & $\begin{array}{c}\text { Adjusted } R \\
\text { Square }\end{array}$ & $\begin{array}{c}\text { Std. Error of } \\
\text { the Estimate }\end{array}$ & Pembahasan \\
\hline 1 & $\mathbf{. 7 0 8}$ & $\mathbf{. 5 0 1}$ & .486 & 4.836 & Karakteristik Individu \\
\multicolumn{2}{l}{ Sumber: pengolahan data }
\end{tabular}

Sesuai tabel 2 diperoleh koefisien korelasi nilai $r=0,708$ maknanya terdapat hubungan yang kuat dan positif antara karakteristik individu terhadap kinerja pegawai pada Kantor Dinas Kependudukan dan Pencatatan Sipil Pematangsiantar. Berdasarkan tabel 2 koefisien determinasi (KD) oleh disiplin kerja 0,501 artinya tinggi rendahnya kinerja pegawai pada Kantor Dinas Kependudukan dan Pencatatan Sipil Pematangsiantar sebesar 50,1\%
Hasil analisis deskriptif kualitatif mengenai karakteristik individu pada Dinas Kependudukan dan Pencatatan Sipil Pematangsiantar pada parameter jawaban baik. Nilai tertinggi pada dimensi tingkat keseriusan dan kesadaran dengan indikator kesadaran terhadap pekerjaan Sedangkan taraf rataan terendah pada parameter jawaban cukup baik berada pada dimensi tingkat keseriusan dan kesadaran dengan indikator keseriusan dalam melakukan pekerjaan 


\section{SULTANIST: Jurnal Manajemen dan Keuangan, Vol 9 (1), Juni 2021}

\section{Kinerja Pegawai}

Hasil analisis deskriptif kualitatif tentang kinerja pegawai pada Dinas Kependudukan dan Pencatatan Sipil Pematangsiantar pada parameter jawaban baik. Untuk parameter tertinggi pada dimensi Sasaran Kinerja Pegawai (SPK) dengan indikator kerapian dalam melakukan pekerjaan. Nilai terendahjuga terdapat pada dimensi Sasaran Kinerja Pegawai (SPK) dengan indikator ketepatan waktu dalam melakukan pekerjaan.

\section{SIMPULAN DAN SARAN}

\section{Simpulan}

Hasil model perhitungan jalur dengan regresi, menunjukkan adanya pengaruh positif antara disiplin kerja dan karakteristik individu terhadap kinerja pegawai pada Dinas Kependudukan dan Pencatatan Sipil Pematangsiantar. Hasil analisis regresi linier sederhana, menyatakan adanya pengaruh positif antara disiplin kerja terhadap kinerja pegawai dan pengaruh positif antara karakteristik individu terhadap kinerja pegawai pada Dinas Kependudukan dan Pencatatan Sipil Pematangsiantar. 5. Hasil analisis koefisien korelasi diperoleh hasil yaitu hubungan yangkuat dan positif antara disiplin kerja dan karakteristik individu terhadap kinerja pegawai pada Dinas Kependudukan dan Pencatatan Sipi Pematangsiantar. Sedangkan perihal lain mempengaruhi kinerja pegawai seperti motivasi, komunikasi tidak diteliti dalam penelitian ini. Hasil pengujian hipotesis secara parsial dengan uji $\mathrm{t}$ menunjukkan adanya pengaruh positif antara disiplin kerja dan karakteristik individu terhadap kinerja pegawai pada Dinas Kependudukan dan Pencatatan Sipil Pematangsiantar.

\section{Saran}

Untuk meningkatkan disiplin kerja pegawai pada Dinas Kependudukan dan Pencatatan Sipil Pematangsiantar, sebaiknya pimpinan perlu melakukan pengawasan secara berkala agar pegawai lebih disiplin dalam mematuhi peraturan jam kerja, pegawai juga harus menimbulkan rasa tanggung jawab dalam menaati peraturan dalam organisasi serta perlu adanya penambahan jadwal finger print setelah istirahat makan siang. Untuk lebih memperbaiki karakteristik individu pegawai pada Dinas Kependudukan dan Pencatatan Sipil Pematangsiantar sebaiknya pimpinan lebih mengingatkan atau menegur pegawai agar bersikap bijaksana dalam menghadapi masalah. Untuk dapat meningkatkan kinerja pegawai pada Dinas Kependudukan dan Pencatatan Sipil Pematangsiantar, terutama pada ketepatan waktu dalam menyelesaikan pekerjaan sebaiknya pegawai tidak menunda pekerjaan dan pegawai harus bersikap inisiatif terhadap pekerjaan yang dilimpahkan kepadanya. Saat memberikan pelayanan sebaiknya pegawai lebih memperhatikan kelengkapan berkas yang akan dikerjakan, jika tidak memenuhi persyaratan maka segera beritahu kepada orang yang bersangkutan.

\section{DAFTAR PUSTAKA}

Bangun, Wilson. 2012. Manajemen Sumber Daya Manusia.Jakarta: Erlangga.

Desyinta, Devi, dkk. 2019. Pengaruh Karakteristik Individu Dan Lingkungan Kerja Terhadap Kinerja Pegawai Pada Badan Pengelolaan Pajak Dan Retribusi Daerah Upt Samsat Pematangsiantar. Jurnal Maker.Volume 5, Nomor 1

Hanum, Latifa, dkk. 2016. Pengaruh Kepemimpinan Dan Disiplin Kerja Terhadap Kinerja Pegawai pada Kantor Kementrian Agama Kota Pematang Siantar. Jurnal Maker, 2(2).

Kasmir, 2016. Manajemen Sumber Daya manusia. Cetakan Pertama.

Jakarta: Penerbit Grafindo Persada.

Lie, D. et al. (2019) 'The Impact of Work Discipline and Work Ethic on the Teacher Performance of Sultan Agung Pematangsiantar Private Middle School Teachers T.A. 2018/2019', International Journal of Business Studies, 3(3), pp. 125-135. doi: 10.32924/ijbs.v3i3.83.

Peraturan Daerah Kota Pematangsiantar No. 4 Tahun 2001, tentang susunan organisasi 


\section{SULTANIST: Jurnal Manajemen dan Keuangan, Vol 9 (1), Juni 2021}

dan tata kerja kantor-kantor kota Pematangsiantar.

Keputusan Walikota Pematangsiantar No. 24 Tahun 2001. tentang susunan organisasi dan tata kerja kantor-kantor kota Pematangsiantar.

Peraturan Daerah Kota Pematangsiantar No. 3 Tahun 2009 tentang Pembentukan Organisasi di Lingkungan Pemerintahan Kota Pematangsiantar.

Peraturan Pemerintah Nomor 53 Tahun 2010 tentang Disiplin Pegawai Negeri Sipil.

Peraturan Daerah No. 1/1998 tentang Penyelenggaraan Penduduk dalam Rangka Kota madya Tingkat Kota Pematangsiantar.

Peraturan Pemerintah Nomor 30 Tahun 2019 tentang Penilaian Kinerja PNS.

Peraturan Pemerintah No. 9 Tahun 1975 tentang Pelakaksanaan Undang- Undang No 1 tahun 1974 tentang perkawinan.
Peraturan Pemerintah Nomor 30 Tahun 2019 tentang Kinerja Pegawai Negeri Sipil.

Rahman, Abdul. 2013. Psikologis Sosial: Integritasi Pengetahuan Wahyu dan Pengetahuan Empirik. Jakarta: Rajawali Perws.

Robbins. Stephen P. dan Timothy A.Judge. 2017. Perilaku Organisasi Organizational Behavior. Edisi Kelima. Jakarta: Salemba Empat.

Sahir, S. H. et al. (2020) Keterampilan Manajerial Efektif. Medan: Yayasan Kita Menulis.

Sule Ernie Tismawati dan Kurniawan Syaifullah. 2010. Pengantar Manajemen. Cetakan Kedelapan. Edisi Pertama. Jakarta:Kencana

Zainal, Veithzal Rivai, dkk. 2015. Manajemen Sumber Daya Manusia untuk perusahaan dari teori ke praktik. Edisi III, Jakarta: Rajawali Pers. 